\title{
UM PANORAMA DA COMPENSAÇÃO AMBIENTAL NO MUNICÍPIO DE SÃO PAULO
}

\author{
AN OVERVIEW OF ENVIRONMENTAL COMPENSATION IN THE CITY OF SÃO PAULO
}

\section{COELHO, Leonardo Loyolla}

Arquiteto-paisagista, mestrando na área de Paisagem e Ambiente pela Pós-Graduação da Faculdade de Arquitetura e Urbanismo da Universidade de São Paulo.

\section{RESUMO}

Este artigo analisa a aplicação do mecanismo legal "Termo de Compromisso Ambiental" (TCA) na cidade de São Paulo, desde sua implantação no município, em 1997. O TCA tem como função básica a compensação dos danos ambientais causados pela retirada de vegetação arbórea para a implantação de empreendimentos urbanos, tanto da iniciativa privada quanto do poder público. Será feito um resumo das possibilidades de compensação ambiental na cidade de São Paulo, das principais ações geradas pelo mecanismo e analisados seus aspectos positivos e deficitários.

Palavras-chave: Legislação ambiental, espaços livres urbanos, compensação.

\begin{abstract}
This article analyzes the application of the legal device "Environmental Commitment Term" (ECT) in the city of São Paulo, since its implementation in 1997. The ECT has as its basic function the compensation of environmental damages that are mainly caused by tree extraction as a result of private and public enterprises (developments). The environmental compensation possibilities, the main actions generated by this device and analyzes of the positive and deficient aspects in São Paulo will be explained.
\end{abstract}

Key words: Environmental legislation, urban open spaces, compensation.

\section{Introdução}

O déficit de espaços livres públicos voltados à recreação, lazer e conservação constitui um problema em diversas metrópoles do mundo, sendo uma constante no Brasil. As cidades de grande porte no país não apresentam, de fato, um sistema de espaços públicos para recreação, lazer e conservação de recursos.

Devido ao porte e à estrutura de gestão do processo de urbanização e à cultura da não priorização de investimentos em projetos de espaços livres públicos voltados ao lazer, o município de São Paulo apresenta dificuldades para intervenções sistemáticas. Em 2006, seriam necessários grandes investimentos do poder público para a implantação de um sistema de espaços livres no município em uma escala adequada.

Além disso, as possibilidades de atuação do poder público no sentido de suprir a carência de espaços livres para lazer na cidade de São Paulo tornam-se cada vez mais restritas devido, sobretudo, à redução do estoque de áreas disponíveis para tais fins. Essa redução ocorre seja pelo avanço do processo de urbanização desordenado sobre as áreas restantes do município, seja pela degradação das áreas existentes, seja ainda pela sua utilização desses espaços para outros fins pelo próprio poder público'.

A escassez de recursos e a postura da não priorização das áreas livres públicas destinadas ao lazer vêm se intensificando na cidade de São Paulo, sendo que, desde a década de 1980, a quantidade dos investimentos públicos para a construção de novos parques e praças reduziu significativamente ${ }^{2}$. 
Ao mesmo tempo em que, nesse período, os investimentos públicos em áreas de lazer caíram em São Paulo, tem-se, por outro lado, um aumento considerável na demanda por esse tipo de espaço, desencadeada principalmente pela expansão das áreas urbanizadas periféricas e adensamento do tecido urbano existente ${ }^{3}$. Dentre as poucas iniciativas recentes (entre os anos de 2000 a 2005) voltadas para o aumento de espaços livres para lazer em São Paulo, pode-se citar:

- O Programa Centro de Bairro, realizado pela Empresa Municipal de Urbanização - Emurb entre 2003 e 2004, no qual foram executadas 48 praças em diversas regiões da cidade, sendo grande parte reformas ou aproveitamento de áreas livres já pertencentes à prefeitura;

- O Parque da Juventude, projeto da arquiteta-paisagista Rosa Grena Kliass, financiado pelo Governo do Estado e inaugurado em 2004. Localizado no terreno do antigo presídio do Carandiru, o parque possui um padrão de qualidade de implantação raramente visto em projetos do gênero existentes na cidade.

Embora se devam considerar as dificuldades impostas pelo porte de cidades como São Paulo em face à necessidade de suprir a carência de espaços livres, pode-se verificar, tanto no contexto internacional como nacional, variados mecanismos que podem colaborar para amenizar tal problema. Dentre os diversos instrumentos possíveis, merece destaque o Termo de Compromisso Ambiental (TCA), mecanismo legal que corresponde à síntese dos trabalhos relacionados à compensação ambiental desenvolvidos no município até o ano de 1997.

\section{Definição}

TCA consiste em: "um documento a ser firmado entre o Poder Público e pessoas físicas ou jurídicas, resultante da negociação de contrapartidas nos casos de autorização prévia para supressão de espécies arbóreas" ${ }^{\prime 4}$.

Sua função básica é compensar os danos ambientais causados pela retirada de vegetação arbórea para a implantação de empreendimentos urbanos, tanto da iniciativa privada, quanto do poder público.

Pode-se dizer que, com a aplicação do TCA, passa a ser atribuído à vegetação urbana um valor de troca, e que, de certo modo, isso equivale a dizer que a Natureza passa a ser reconhecida como mercadoria. Esta atribuição, no entanto, não é utilizada com interesses especulativos, mas sim com o intuito de atenuar conflitos sociais provenientes do processo predatório e desigual de ocupação da cidade.

O impedimento da utilização desse valor de troca para fins especulativos é garantido por uma série de procedimentos previstos no próprio texto da legislação compensatória. Para concretizar a compensação devem ser obedecidas várias restrições que têm por objetivo permitir sua aplicação somente em casos mais extremos.

Embora seja utilizado desde quando se definiu a vegetação significativa do município em $1988^{5}$, a utilização sistemática de mecanismos de compensação ambiental ocorre a partir do ano de 19976, sendo intensificada a partir da definição da Lei de Crimes Ambientais, de âmbito nacional ${ }^{7}$. Inicia-se então a preparação dos aparatos legais na esfera municipal que iriam amparar a aplicação dessa lei federal. No ano de 2002 incorpora-se o Termo de Compromisso Ambiental ao texto do Plano Diretor Estratégico do Município, e a partir de então a Secretaria do Verde e Meio Ambiente (SVMA) emite diversas portarias regulamentando procedimentos mais detalhados para as compensações.

Os recursos provenientes das compensações no município de São Paulo são aplicados, basicamente, de 3 modos: 
- Plantio e manutenção de novas mudas, a serem custeadas pelo empreendedor. Estas mudas devem, prioritariamente, ser implantadas dentro do próprio empreendimento gerador da compensação ou em seu entorno imediato. Caso isto não seja possível, o plantio deve ser efetuado em outra região do município. Em todos os casos, a quantia mínima de mudas é de, no mínimo, o dobro do retirado. Esta possibilidade constitui prioridade para os órgãos competentes e representa a maior parte das compensações ambientais efetuadas no município. Por este motivo, também tem sido objeto dos maiores aperfeiçoamentos observados no texto da legislação correspondente.

- Aquisição e doação à prefeitura de novas áreas livres disponíveis no município. Esta possibilidade passou a constituir uma alternativa ao plantio de mudas. Sua concepção baseia-se no princípio de que adquirir um espaço livre e arborizado representa uma forma de aumentar o estoque de áreas sob responsabilidade do município, contribuindo para atenuar o déficit existente.

- Contratação de serviços e obras que viabilizem a implantação de novos espaços livres para lazer na cidade, juntamente com o plantio de uma quantia mínima estipulada de vegetação compensatória. Esta possibilidade surgiv em 2001 , com objetivo básico de viabilizar a implantação de novos espaços livres para lazer em terrenos pertencentes ao Poder Público e também permitir a manutenção dos espaços existentes com essa finalidade.

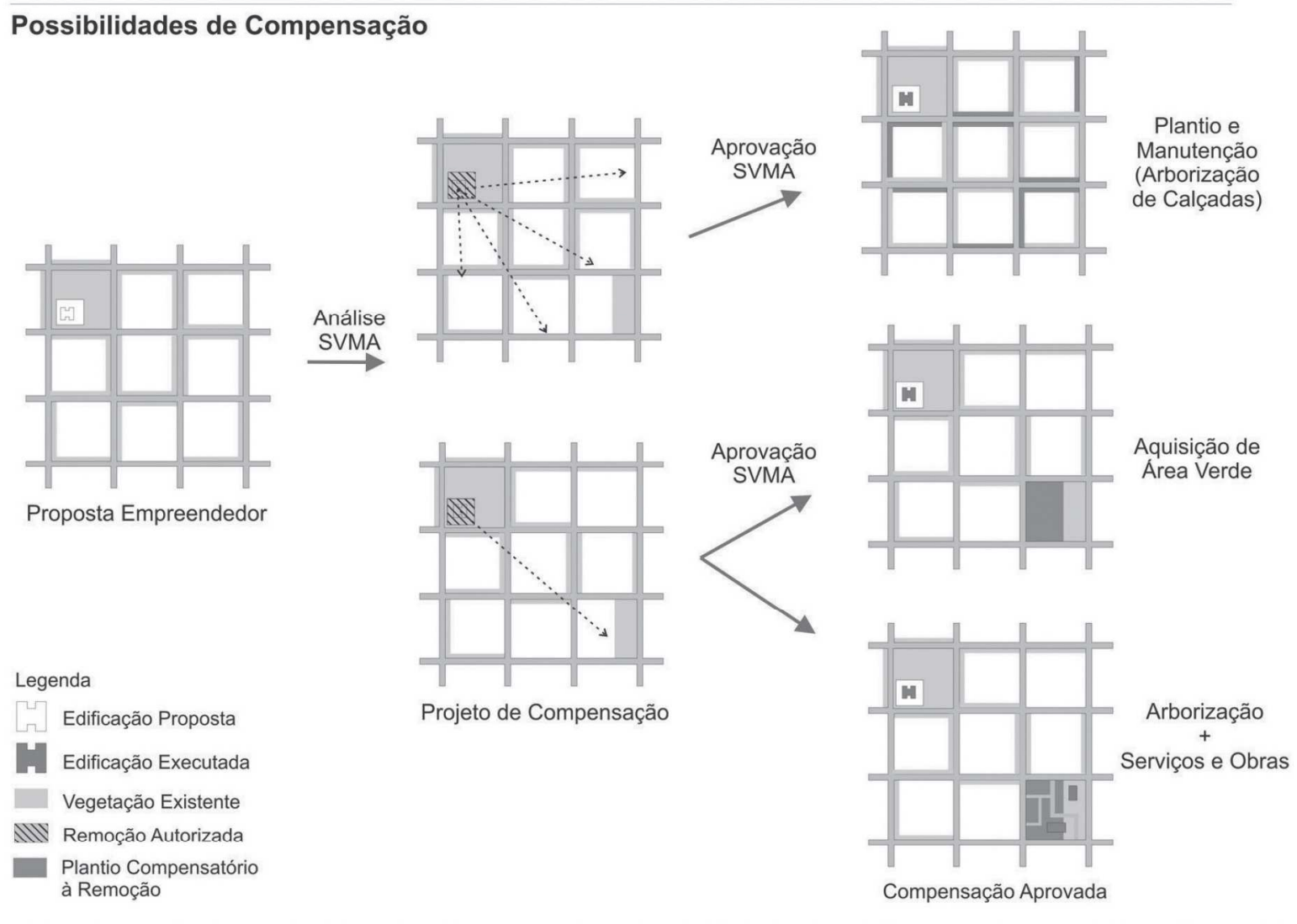

Em todos esses casos, a indicação das áreas de lazer ou terrenos a receberem as benfeitorias provenientes da compensação é feita pelo Departamento de Parques e Áreas Verdes do Município de São Paulo (DEPAVE). A partir do ano de 2005 foi criada uma Câmara de Compensação Ambiental (CCA), composta por um corpo interdisciplinar de técnicos do DEPAVE e da Secretaria do Verde e Meio Ambiente especificamente para estudo dos casos considerados mais relevantes.

A potencialidade mais interessante do uso da compensação ambiental é a possibilidade de direcionar recursos provenientes de regiões da cidade mais bem aparelhadas de infra-estrutura de lazer e arborização para locais onde estas muitas vezes inexistem. 


\section{Projetos de paisagismo e a compensação ambiental}

Estão listados a seguir os principais projetos de logradouros públicos viabilizados por TCAs:

\begin{tabular}{|c|c|c|c|c|c|c|}
\hline Logradouro & $\begin{array}{l}\text { Praça Anna } \\
\text { dos Santos } \\
\text { Figueiredo }\end{array}$ & $\begin{array}{l}\text { Parque da } \\
\text { Vila } \\
\text { Prudente }\end{array}$ & $\begin{array}{l}\text { Parque do } \\
\text { Cordeiro }\end{array}$ & $\begin{array}{l}\text { Parque } \\
\text { Colinas } \\
\text { de São } \\
\text { Francisco }\end{array}$ & $\begin{array}{l}\text { Parque } \\
\text { Jacintho } \\
\text { Alberto }\end{array}$ & $\begin{array}{c}\text { Parque } \\
\text { Pinheirinho } \\
\text { D'Água }\end{array}$ \\
\hline Localização & 1 & 2 & 3 & 4 & 5 & 6 \\
\hline Entrega & 2004 & 2004 & 2005 & 2004 & 2003 & 2005 \\
\hline Autor & $\begin{array}{c}\text { Kruchin } \\
\text { Arquitetura }\end{array}$ & DEPAVE & Raul Pereira & $\begin{array}{l}\text { Núcleo da } \\
\text { Paisagem }\end{array}$ & $\begin{array}{c}\text { Raul } \\
\text { Pereira }\end{array}$ & Raul Pereira \\
\hline Manutenção & ruim & média & ruim & média & boa & média \\
\hline $\begin{array}{l}\text { Uso pela } \\
\text { população }\end{array}$ & pouco & intenso & $\begin{array}{l}\text { fechado } \mathrm{p} / \\
\text { público }\end{array}$ & pouco & intenso & médio \\
\hline $\begin{array}{l}\text { Qualidade de } \\
\text { Execução }\end{array}$ & boa & média & ruim & boa & média & média \\
\hline $\begin{array}{l}\text { Grau de } \\
\text { Execução }\end{array}$ & Concluída & $\begin{array}{c}1^{a} \text { fase } \\
(100 \%) \\
2^{a} \text { efase } \\
\text { aprovada }\end{array}$ & $\begin{array}{c}1^{\circ} \text { fase }(25 \%) \\
2^{a} \text { fase proj. } \\
\text { exec. }\end{array}$ & $\begin{array}{l}\text { Parcial } \\
(90 \%)\end{array}$ & $\begin{array}{c}1^{a} \text { fase } \\
\text { (70\%) } \\
2^{a} \text { fase } \\
\text { aprovadu }\end{array}$ & Parcial (5\%) \\
\hline Área total $\left(\mathrm{m}^{2}\right)$ & $4 \mathrm{mil}$ & $59 \mathrm{mil}$ & $32 \mathrm{mil}$ & $47,2 \mathrm{mil}$ & $37,6 \mathrm{mil}$ & $350 \mathrm{mil}$ \\
\hline
\end{tabular}

Fontes: Prefeitura do Município de São Paulo - Departamento de Parques de Áreas Verdes, 2005 / Visitas de campo do pesquisador entre os anos de 2005 e 2006

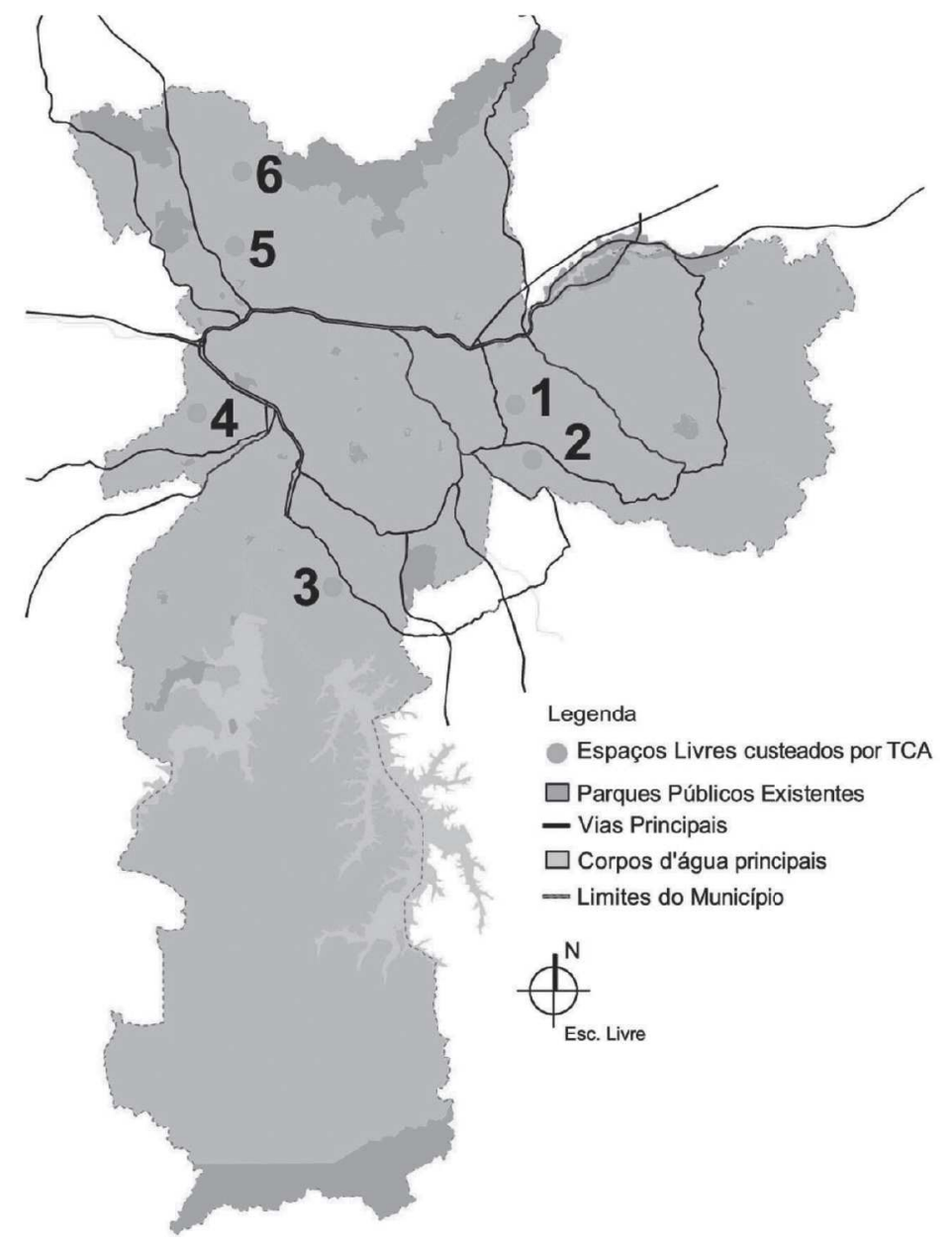




\section{Praça Anna dos Santos Figueiredo}

Localiza-se no Jardim Anália Franco, área da Zona Leste paulistana com empreendimentos de alto padrão, em processo de crescimento desde o final da década de 1990.

A praça foi executada em compensação à retirada de árvores durante a implantação do Campus da Universidade Cruzeiro do Sul (Unicsul), tendo sido projetada pelo escritório Kruchin Arquitetura, responsável também pelas edificações e plano diretor da Unicsul. Constitui o único dos projetos completamente executado.

A linguagem projetual utilizada é bastante diferente daquela estabelecida pelo Depave, caracterizando-se pela maior liberdade projetual e conceitual.

Sua implantação entre duas avenidas de tráfego intenso, em posição elevada em relação aos principais acessos, traduz-se em pouca utilização. Apresenta manutenção ruim e vem sofrendo intenso processo de deterioração desde meados de 2005.
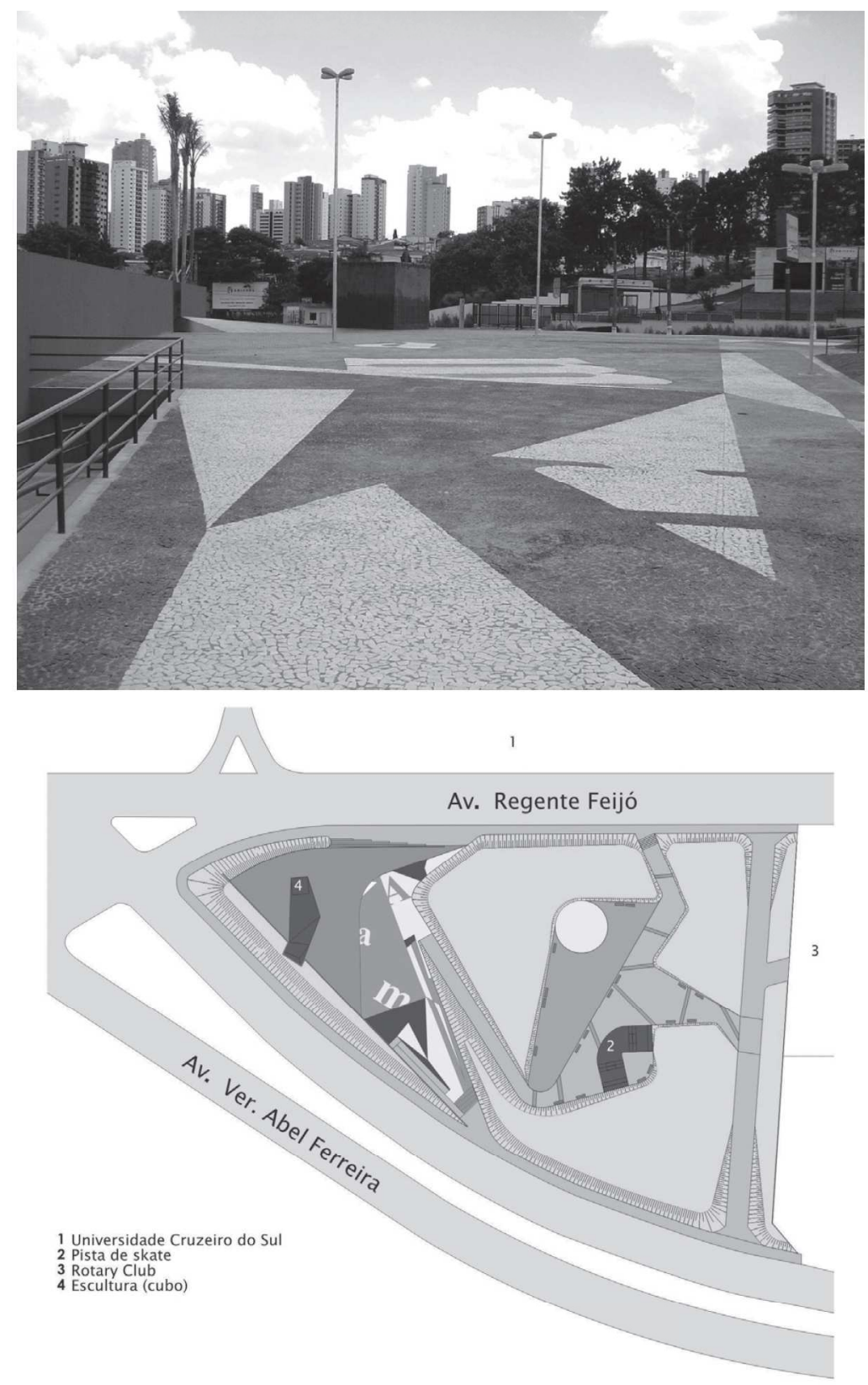

Foto e desenho: Leonardo Loyolla Coelho, janeiro de 2005 


\section{Parque da Vila Prudente (Natalícia Diogo)}

Localizado na Zona Leste paulistana, em área verticalizada em expansão, ocupada principalmente pela classe média desde a década de 1980. É o único parque resultante de compensações ambientais projetado pela equipe DEPAVE.

É bastante utilizado pela população de todas faixas etárias, adquirindo caráter de parque regional, em conjunto com Centro Desportivo Municipal em terreno contíguo. A parte atualmente aberta ao público corresponde a uma primeira etapa que prevê futura integração com terrenos públicos adjacentes. Sua manutenção é mediana, existindo, por exemplo, vários casos de mudas mortas repostas pela própria comunidade local.
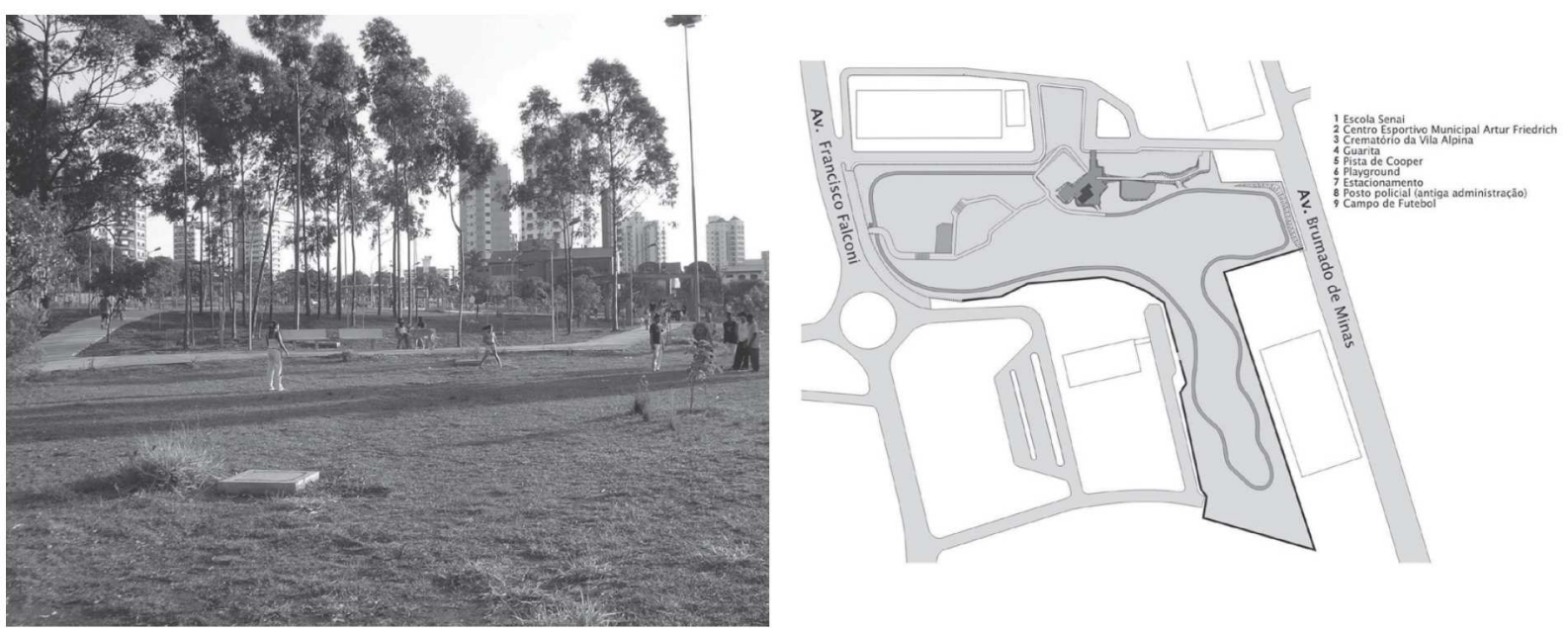

Foto e desenho: Leonardo Loyolla Coelho, setembro de 2005

\section{Parque do Cordeiro}

Dividido em dois setores (leste e oeste), o parque teve sua implantação viabilizada em grande parte devido à mobilização da Sociedade de Amigos do Bairro do Jardim Petrópolis e dos Estados (SAJAPE).

Constitui o primeiro parque cuja implantação foi custeada devido a TCAs. Executado de forma fragmentada pela prefeitura, após uma série de percalços, o parque teve sua porção leste parcialmente construída, embora ainda não tenha sido aberta ao público devido, entre outros motivos, a problemas para definição de seu conselho gestor.

A parte oeste ainda está em fase de aprovação do projeto executivo.

\section{Parque Colinas de São Francisco}

Localizado na Vila São Francisco, bairro da zona oeste da cidade que vem sofrendo diversas transformações devido à construção de vários empreendimentos residenciais - sobretudo vilas e torres - o parque apresenta elevada qualidade de projeto e execução.

Sua utilização pela população local, no entanto, é pequena - talvez um reflexo das estruturas autônomas de lazer privado do entorno - e as entradas que permitiriam acesso ao público mais geral encontram-se fechadas.

A execução da obra do parque não foi totalmente completada, sendo que as edificações construílas não foram ocupadas e alguns equipamentos existentes não foram instalados e estão deteriorando. A manutenção também é bastante restrita em alguns trechos. Como resultado de compensações ambientais, foram também executadas em áreas contíguas duas praças de caráter local, sendo uma delas mais utilizada pela população que o próprio parque. 


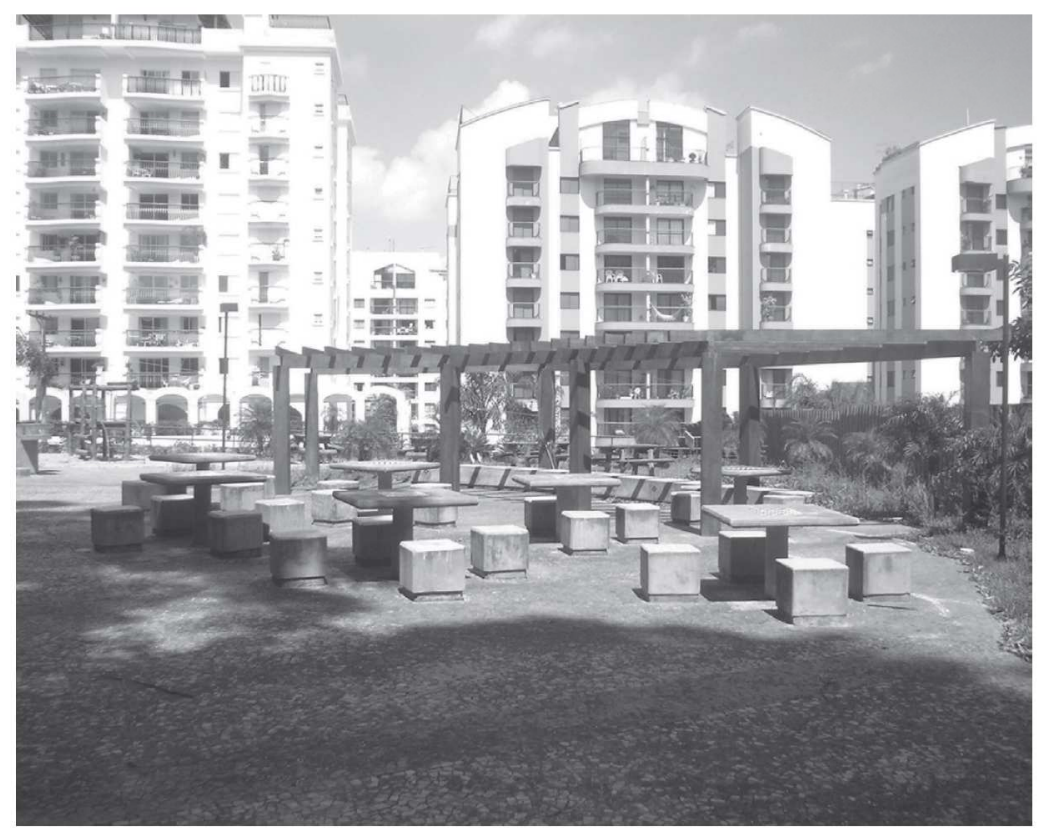

Foto: Leonardo Loyolla Coelho, marcço de 2006

\section{Parque Jacinto Alberto}

Praça transformada em parque graças a um TCA proveniente de empreendimento imobiliário no bairro de Pirituba. Foi implantado apenas parcialmente, tendo sido suprimidos alguns equipamentos de lazer como quadras e playgrounds. Localizado em área de uso residencial, é bastante usado pela comunidade local, sobretudo os jovens, que utilizam a pista de skate implantada. A área possui manutenção adequada, embora o edifício administrativo, a exemplo dos outros parques de TCA, não seja utilizado.
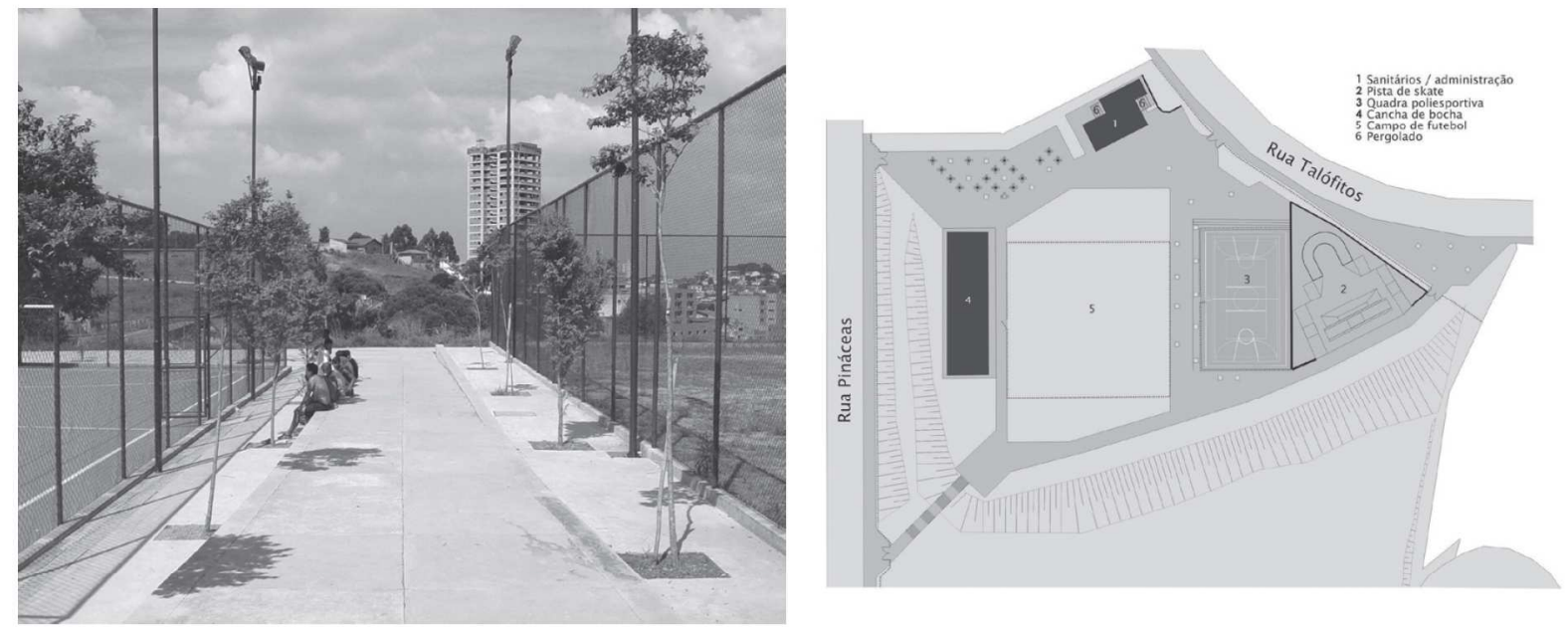

Foto e desenho: Leonardo Loyolla Coelho, abril de 2005

\section{Parque Pinheirinho D'água}

Seu projeto inicial foi resultante do trabalho conjunto de professores e alunos da pós-graduação da FAUUSP, profissionais de diversas áreas de atuação (inclusive da prefeitura do município) e da comunidade de baixa renda do entorno, na região do bairro de Perus. $O$ detalhamento do projeto foi realizado pelo escritório do arquiteto paisagista Raul Pereira, que também participara das dinâmicas do projeto inicial. Foram consideradas em sua elaboração importantes variáveis ambientais, como a recomposição da mata ciliar do córrego que atravessa e dá nome ao parque. 
Sua execução até o momento foi fragmentada e bastante restrita se considerarmos a extrema carência de espaços livres para lazer no entorno. A maior parte do projeto ainda aguarda aprovação dos órgãos públicos. A comunidade local tem auxiliado na proteção de invasões ao terreno previsto para implantação do restante do parque.

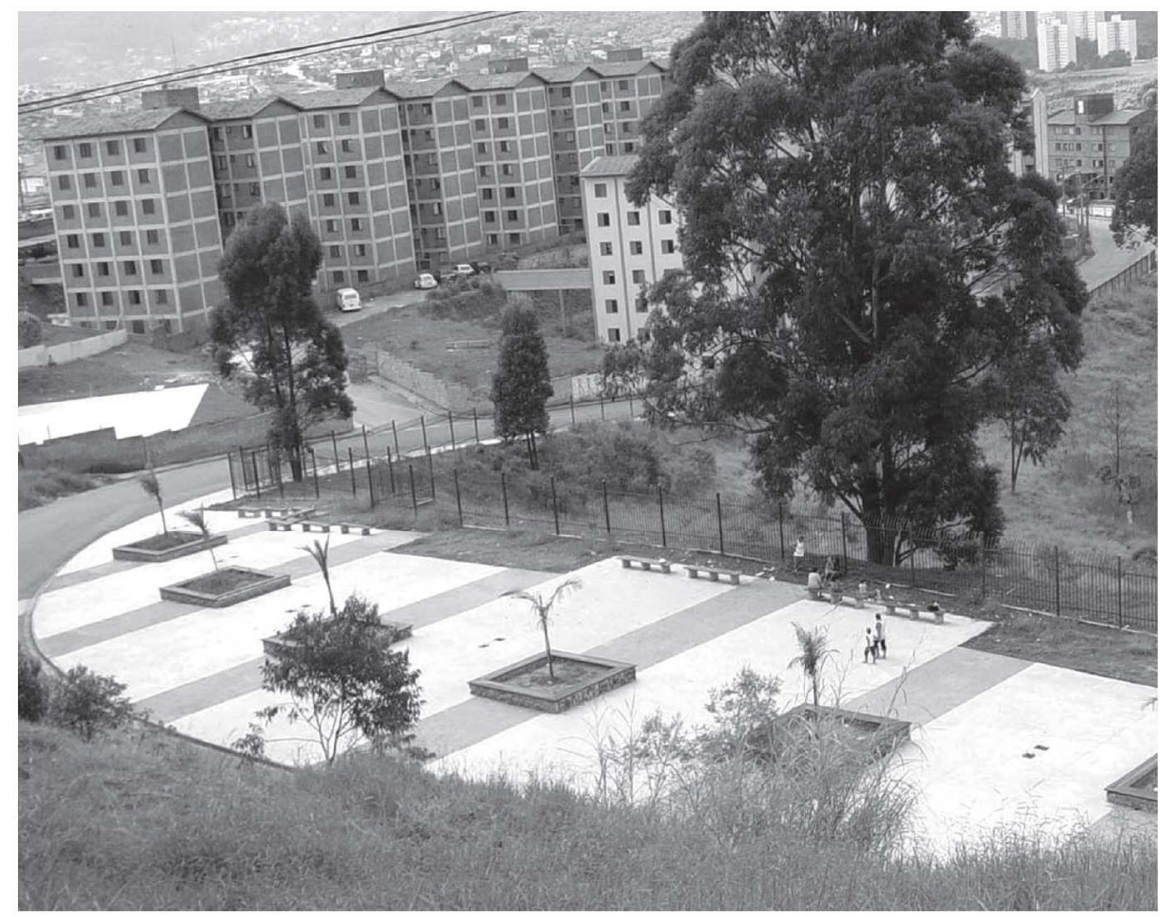

Foto: Leonardo Loyolla Coelho, abril de 2005

Com relação às compensações através do plantio de novas mudas, têm-se, em geral, ações cujo porte individual é menor que os casos de obras e serviços anteriormente citados. Apesar disso, os casos de arborização representam conjuntamente a maior parcela das compensações.

Merecem destaque, dentre cerca de 700 casos existentes até o ano de $2005^{8}$ :

- Arborização com cerca de 750 árvores no bairro do Brooklin Novo em função da implantação de 5 vilas de alto padrão em gleba no Alto da Boa Vista. Projeto a encargo da Gobbi Paisagismo. A existência de grande área de cobertura arbórea no entorno do empreendimento obrigou que a distribuição das árvores compensatórias fosse feita em áreas do entorno, sob orientação da subprefeitura. Devido à depredação, cerca de 30\% dos exemplares tiveram de ser repostos pelo empreendedor, índice considerado alto.

- Arborização do entorno do Hospital Alemão Oswaldo Cruz em função de obras de expansão da unidade. Projeto da arquiteta paisagista Miranda Magnoli. Envolveu longa negociação com órgãos públicos e um trabalho de esclarecimento junto ao empreendedor e arquitetos com relação à importância da preservação de exemplares arbóreos.

- Arborização com cerca de 1.000 árvores no bairro da Freguesia do Ó em função de empreendimento com várias torres residenciais realizado por cooperativa da região. Projeto a encargo da Gobbi Paisagismo. A identificação das áreas do entorno a receberem a compensação foi facilitada pela carência de arborização do local. A ação dos moradores na conservação das árvores tem sido muito importante.

\section{Análise}

A aplicação do TCA no município de São Paulo ainda encontra uma série de desafios a serem enfrentados. Dentre eles pode-se citar a falta de estrutura adequada do poder público para 
aplicá-lo, estando a aprovação dos projetos ainda muito sujeita a entraves burocráticos e desorganizações internas.

Além disso, permeia não só entre a população leiga como também entre os próprios técnicos envolvidos na aplicação do mecanismo a idéia de que a arborização urbana, mesmo isoladamente, tem condições de resolver boa parte dos problemas referentes a espaços livres para lazer no município.

Outro obstáculo a ser enfrentado é a falta de visão da cidade como um sistema de espaços livres, fazendo com que as ações sejam fragmentárias e percam força quando analisadas em conjunto. Exemplo disso é o fato de que alguns espaços livres viabilizados por TCA têm baixa utilização enquanto outros, em áreas com demandas efetivas, sequer saíram do papel ou não tiveram ainda suas portas abertas ao público mesmo tendo sido parcialmente executados.

Tal restrição começa a ser vencida a partir da implantação da Câmara de Compensação Ambiental. Nela são apontados critérios mais específicos de uso do mecanismo, tais como a adoção de bacias hidrográficas como delimitação para a área de aplicação das compensações.

mecanismo ainda apresenta um longo caminho a percorrer até que seus resultados mostremse mais efetivos perante o porte do município. Deve-se considerar o fato de que a atuação dos TCAs restringe-se à parcela da cidade onde a fiscalização é mais efetiva, sobretudo no chamado vetor sudoeste do município, onde, não por coincidência, a renda da população também é mais elevada. Essas áreas também costumam apresentar maiores porcentagens de cobertura arbórea existente. Isto acaba por gerar, em diversos casos, problemas para identificação de lugares para plantio de novos exemplares no entorno imediato dos empreendimentos. Enquanto isso, a imensa maioria da cidade ainda está sujeita a um intenso processo de devastação da cobertura arbórea remanescente. A compensação ambiental pode auxiliar na atenuação deste problema, mas isto só será possível na escala desejada a partir de uma fiscalização mais intensa das áreas periféricas do município.

A manutenção das áreas viabilizadas por compensação ambiental também constitui um problema. Embora a legislação estabeleça um prazo no qual a manutenção das áreas permaneça sob responsabilidade do empreendedor responsável pela compensação, observa-se que quando este limite expira, as áreas deterioram-se rapidamente. Tal fato ocorre porque, a exemplo de boa parte da cidade de São Paulo, não há continuidade na manutenção dos espaços livres por parte do poder público.

Embora apresente diversos aspectos a serem aperfeiçoados, a compensação ambiental em São Paulo tem mostrado características positivas que podem contribuir para a melhoria dos espaços livres para lazer no município.

Além de favorecer e potencializar a distribuição mais adequada de espaços livres, a aplicação do TCA pode contribuir, ainda que lentamente, para o incremento do estoque de áreas livres da cidade.

Deve-se destacar também, que uma das razões da efetividade de ações relativas à compensação ambiental deve-se à sua característica de delegar à iniciativa privada (mais especificamente ao empreendedor) a responsabilidade da implantação e manutenção das áreas livres, desvinculando-a parcialmente do poder público, que passa a cumprir a função de fiscalizador.

Por fim, o Termo de Compromisso Ambiental apresenta como uma de suas principais características a constante alteração de seu texto em curtos espaços de tempo. Suas evoluções baseiam-se em aplicações bem sucedidas de outros lugares do país, sobretudo Rio de Janeiro, Curitiba e Porto Alegre. Isto tem permitido saltos na qualidade da legislação, que gradativamente tem se tornado uma das mais detalhadas do gênero no país. Os maiores detalhamentos, no entanto, têm sido focados nos aspectos técnico-agronômicos do processo, sem aprofundar tanto as questões de 
cunho urbanístico e paisagístico. Através das freqüentes mudanças de caráter complementar, o TCA acaba por atender aos interesses específicos de cada gestão sem que, no entanto, estas se prejudiquem de forma estrutural. Consegue-se desse modo algo raro no poder público: uma certa continuidade permeando diferentes gestões.

\section{Notas}

(1) SÃO PAULO (Cidade). Secretaria Municipal do Verde e Meio Ambiente - Atlas Ambiental Municipal 2000. São Paulo: SVMA, 2000.

(2) BARTALINI, Vladimir. Parques públicos municipais de São Paulo. Tese (Doutorado). São Paulo: FAUUSP, 1999.

(3) MEYER, Regina Maria Prosperi. São Paulo Metrópole. São Paulo: Edusp, 2004.

(4) PMSP. Plano Diretor Estratégico do Município de São Paulo. Lei n. 13.430 de 13 de setembro de 2002. Cap. III - Seção XIII - "Dos Instrumentos de Gestão Ambiental", art. 251.

(5) SÃO PAULO (Estado) Secretaria do Meio Ambiente / Secretaria Municipal de Planejamento - Vegetação Significativa no Município de São Paulo. São Paulo, 1988.

(6) Informação fornecida por entrevista pelo engenheiro agrônomo Carlos Alberto da Silva Filho, coordenador do Núcleo para a Legislação de Proteção e Fomento da Vegetação - Depave até o ano de 2005, e um dos responsáveis pelo desenvolvimento do TCA.

(7) Lei Federal n. 9.605, de 12 de fevereiro de 1998.

(8) Vide nota 6.

\section{Bibliografia}

BARTALINI, Vladimir. Parques públicos municipais de São Paulo. 1999. Tese (Doutorado) - Faculdade de Arquitetura e Urbanismo, Universidade de São Paulo, São Paulo, 1999.

MEYER, Regina Maria Prosperi. São Paulo Metrópole. São Paulo: Edusp, 2004. p. 60-61.

SÃO PAULO (Cidade). Plano Diretor Estratégico do Município de São Paulo. São Paulo: PMSP, Lei n. 13.430 de 13 de setembro de 2002.

- Atlas Ambiental Municipal 2000. São Paulo: Secretaria Municipal do Verde e Meio Ambiente (SVMA), 2000.

SÃO PAULO (Estado). Vegetação significativa no município de São Paulo. São Paulo: Secretaria do Meio Ambiente/ Secretaria Municipal de Planejamento, 1988. 